\title{
ACUPUNCTURE AND MOXIBUSTION
}

\author{
J. H. BENNETT, M.B., B.Ch., B.A.O., D.P.H., D.I.H. \\ Colonel, late R.A.M.C.
}

VERY few Medical Officers serve in the East without at sometime coming into contact with Chinese medicine. This mainly consists of acupuncture and moxibustion. Acupuncture is the insertion into the body of the patient of needles made of stone, wire, steel, silver or gold. Moxibustion is the heating of the skin by igniting balls, sticks or rolls of dried moxa. Moxa is some form of dried herbs and grasses. The distance between the glowing end of the moxa 'cigarette' and the skin should be such that the patient only. feels a comfortable warmth.

These therapeutical methods-acupuncture and moxibustion-have been handed down through the ages, from the legendary Emperor Huang $\mathrm{Ti}$, two thousand years ago. Although very different, the two methods are sometimes used together.

Huang Ti wrote a medical classic the Book of internal medicine (Nei Ching) in which mention is made of stone needles. This book is really a summary of the Chinese knowledge of anatomy, physiology, pathology, diagnosis and treatment as was known at that time, and laid the foundation of Chinese medicine, and contains detailed descriptions of acupuncture and moxibustion.

In the Tsin Dynasty in A.D. 256 a further book was written entitled An introduction to acupuncture and moxibustion. During the Tang Dynasty (618-907) lectures and writings on the medical arts of acupuncture and moxibustion were numerous. The Sung Dynasty in 1026 produced a physician, Wang Wai-Yi, who wrote a book entitled Illustrated manual on the points for acupuncture and moxibustion as found on the bronze figure. He made two bronze figures for use in teaching, each having the location for points for acupuncture and moxibustion. Acupuncture and moxibustion continued in popularity through the Ming Dynasty (1368-1644) until the Ching (1644-1911) when the feudal Emperors stated " that the body of royalty must not be needled".

An introduction of Western medicine at the beginning of the present century, saw a decline in the practice of acupuncture and moxibustion. Now, however, under the communist party regime, co-operation of Western medicine and Chinese traditional medicine is urged, and since 1955 a Research Institute of Acupuncture and Moxibustion has been formed in Peking.

The method of treatment by acupuncture and moxibustion is very complicated, and depends upon the way doctors of traditional Chinese medicine divide the viscera into two groups-the Tsang and Fu. The Tsang are the heart, liver, spleen, lung and kidneys-five in number. The $\mathrm{Fu}$ are the stomach, large intestine, small intestine, gallbladder, urinary bladder and the San Chiao - six in number. The San Chiao is a combination of three sections, one at the cardiac end of the stomach, one within the stomach and one around the ureters. The pericardium is often added making the number up to 12 . These internal organs are all connected by what are known as principal channels or 'ching mai', which enter the Tsang and the Fu in various directions all through the human body. It is along the direction of these channels that the vital energy (the Chi) blood and nutriment circulate and cause the body to function as an organic whole. They run from the chest to the hands, from the hands to the head, from the head to the feet and from the feet to the abdomen or to the chest. Each principal channel has a 
special name, and in them the vital force flows day and night in accordance with definite rules. There are 14 of these principal channels. All the points for acupuncture and moxibustion are located along them-the greatest number of points along one channel is 67 , and the least number is nine.

Diagnosis in traditional Chinese medicine is based on the fact that diseases are due to internal or external causes. The internal causes are joy, anger, worry, thought, grief, surprise and fear. These give rise to symptoms on the surface of the body, internally or along a specific channel.

To' diagnose disease from these symptoms the Chinese doctor of traditional medicine uses four methods or Szy Chen. To see, to hear, to ask, to feel the pulse-the last is the most important.

Having located the disease, the doctor then carries out acupuncture or moxibustion on the appropriate point, both along the affected and principal channels as his chinese medicine teaches. The position is complicated by the fact that acupuncture on one point may cure several kinds of disease, but to cure one kind of disease may require acupuncture on several points. Therefore medical theory must be combined with clinical experience in choosing the correct points for acupuncture and moxibustion. One must correctly select the points needing treatment to get the best results.

Having selected the points for acupuncture and moxibustion, certain principles must be remembered, and they differ with the diseases. If the patient's illness is caused by weakness (hsu) the acupuncture should stimulate, and if caused by superfluity (shih) the acupuncture should relax. Diseases caused by 'shih' would include gastric hyperacidity, spasm and pains: acupuncture should relax the patient. Hsu would include motor paralysis, sensory paralysis and hypoacidity: acupuncture should stimulate.

\section{Needle manipulation}

When the needle pierces the skin, the best results are obtained if the patient feels pain, numbness or shock. There are many ways to produce either stimulation or relaxation by acupuncture. The commonest is by inserting the needle in or against the direction of the vital force. Setting the needle in the direction of the force, and pushing or twisting it stimulates, whilst setting it against the direction of the flow and pushing or twisting it, relaxes.

The writers are at great pains to point out that acupuncture seems simple, but great skill is required in actual practice to get good results. For instance all points differ in the depth to which the needle may be inserted; also, there are forbidden points-which are unsuitable for acupuncture and moxibustion.

The methods of moxibustion are varied and the selection of points is the same as for acupuncture. The patient should not be burned, he should only feel a comfortable warmth, and the time required for moxibustion at each point should be 30 minutes, but may vary. My translation goes on at great length, to list the diseases that benefit from acupuncture and moxibustion and include nervous, gynaecological, skin or parenchymal disease. The final words read, "Medical scientists have not yet found a definite explanation of their therapeutic value".

Were the Ching emperors correct when they issued the edict painted in red with the vermilion brush "The body of royalty must not be needled. Pay attention to your Emperor and tremble"? 
Reproduced from the Journal of the College of General Practitioners, No. 61, March, 1967, by kind permission of the Editor.

\section{REFERENCES}

1. Research papers, Academy of traditional Chinese Medicine, Peking.

2. Foreign Language Press, Peking.

3. Chinese Therapeutical Methods of Acupuncture and Moxibustion-Translations, Peking, 1960-62.

\section{PRESENTATION TO Mr. J. H. GRUNDY}

\section{Lately Lecturer in Entomology, Royal Army Medical College}

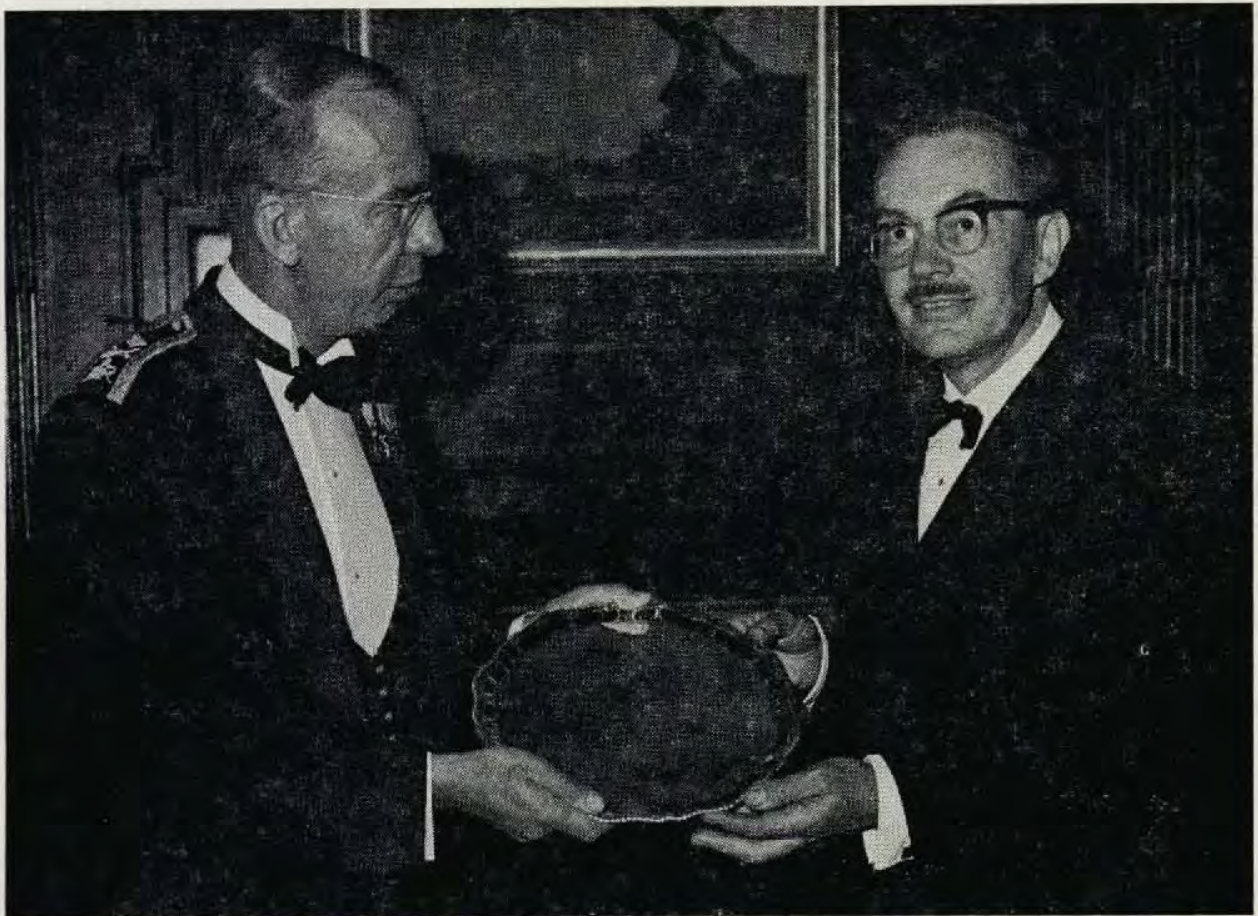

At a Regimental Dinner Night in the R.A.M.C. Headquarter Mess on 24th October, 1967, Mr. John Hull Grundy, who recently retired from the staff of the Royal Army Medical College after twenty-five years as Lecturer in Entomology, was formally " dined out".

Immediately before the guests assembled for dinner, Major-General K. F. Stephens, Commandant of the Royal Army Medical College, acting for the Director-General, Army Medical Services, formally presented Mr. Grundy with a silver salver as a farewell present from officers of the Corps.

The salver was engraved-

"Presented to Mr. John Hull Grundy, F.R.S.A., F.R.E.S., by the Director-General Army Medical Services and the Officers, past and present, Royal Army Medical Corps, on the occasion of his retirement-23rd August, 1967'". 